\title{
Detection of scabies: A systematic review of diagnostic methods
}

\author{
Victor Leung $\mathrm{MD}^{1}$, Mark Miller $\mathrm{MD}^{2}$
}

\begin{abstract}
V Leung, M Miller. Detection of scabies: A systematic review of diagnostic methods. Can J Infect Dis Med Microbiol 2011;22(4):143-146.
\end{abstract}

BACKGROUND: Accurate diagnosis of scabies infection is important for patient treatment and for public health control of scabies epidemics.

OBJECTIVE: To systematically review the accuracy and precision of history, physical examination and tests for diagnosing scabies.

METHODS: Using a structured search strategy, Medline and Embase databases were searched for English and French language articles that included a diagnosis of scabies. Studies comparing history, physical examination and/or any diagnostic tests with the reference standard of microscopic visualization of mites, eggs or fecal elements obtained from skin scrapings or biopsies were included for analysis. Data were extracted using standard criteria.

RESULTS: History and examination of pruritic dermatoses failed to accurately diagnose scabies infection. Dermatoscopy by a trained practitioner has a positive likelihood ratio of 6.5 (95\% CI 4.1 to 10.3$)$ and a negative likelihood ratio of 0.1 (95\% CI 0.06 to 0.2$)$ for diagnosing scabies. The accuracy of other diagnostic tests could not be calculated from the data in the literature.

CONCLUSIONS: In the face of such diagnostic inaccuracy, clinical judgment is still practical in diagnosing scabies. Two tests are used - the burrow ink test and handheld dermatoscopy. The burrow ink test is a simple, rapid, noninvasive test that can be used to screen a large number of patients. Handheld dermatoscopy is an accurate test, but requires special equipment and trained practitioners. Given the morbidity and costs of scabies infection, and that studies to date lack adequate internal and external validity, research to identify or develop accurate diagnostic tests for scabies infection is needed and justifiable.

Key Words: Diagnosis; Scabies; Systematic review

Scabies, caused by the mite Sarcoptes scabiei var. hominis, is one of $\checkmark$ the many causes of pruritic dermatoses. The discovery of $S$ scabiei in 1687 showed for the first time that disease could be caused by a microorganism (1). Today, as many as 300 million people are infected with scabies annually (2). Children in resource-poor countries are disproportionately affected, and there is evidence that scabies has been a major risk factor for developing poststreptococcal glomerulonephritis $(2-4)$. Globally, the prevalence of scabies is low, and its disease burden is unevenly distributed. Yet, its morbidity, treatment and infection control can be costly and challenging.

Transmission of scabies is primarily mediated by close contact with an infected person (3). In adults, sexual contact is a means of transmission (5). The elderly are also at higher risk, particularly when living in longterm care facilities, where outbreaks can lead to substantial costs and morbidity (6). Secondary skin and soft tissue infections, and institutional outbreaks, add to the costs and suffering $(6,7)$. Rapid diagnosis and immediate treatment of those affected are keys to effective eradication.

The probability of scabies transmission has been estimated to be proportional to the number of mites infecting an individual. In classic scabies, the average number of adult female mites on the body has been estimated

\section{Le dépistage de la gale : une analyse systématique des méthodes diagnostiques}

HISTORIQUE : Il est important de poser un bon diagnostic d'infection par la gale pour traiter le patient et assurer le contrôle des épidémies de gale en santé publique.

OBJECTIF : Analyser systématiquement l'exactitude et la précision des antécédents, de l'examen physique et des tests diagnostiques de la gale.

MÉTHODOLOGIE : Au moyen d'une stratégie de recherche structurée, les chercheurs ont fouillé dans les bases de données de Medline et d'Embase pour trouver des articles en anglais et en français qui incluaient un diagnostic de gale. Les études comparant les antécédents, l'examen physique et les tests diagnostiques, la norme de référence étant la visualisation microscopique des acariens, des œufs ou des éléments fécaux obtenus des grattages cutanés ou des biopsies étaient inclus dans l'analyse. Les chercheurs ont extrait les données selon les critères habituels.

RÉSULTATS : Les antécédents et l'examen des dermatoses pruritiques n'ont pas permis de diagnostiquer correctement l'infection par la gale. La dermatoscopie effectuée par un praticien formé s'associait à un rapport de vraisemblance positif de 6,5 (95\% IC 4,1 à 10,3) et un rapport de vraisemblance négatif de 0,1 ( $95 \%$ IC 0,06 à 0.2) pour diagnostiquer la gale. Il était impossible de calculer l'exactitude des autres tests diagnostiques à partir des données contenues dans les publications.

CONCLUSIONS : Compte tenu d'une telle inexactitude diagnostique, le jugement clinique demeure pratique pour diagnostiquer la gale. Deux tests sont utilisés : le test à l'encre est un test simple, rapide et non effractif qui peut être utilisé pour diagnostiquer un grand nombre de patients. La dermatoscopie portative est un test précis, mais elle nécessite du matériel spécial et des praticiens formés. Étant donné la morbidité et le coût de l'infection par la gale et puisque les études jusqu'à maintenant sont dénuées de validité interne et externe, des recherches pour déterminer ou élaborer des tests diagnostiques précis de l'infection par la gale s'imposent et sont justifiables.

to be between five and 15 , but this can approach millions in cases of chronic infection (ie, crusted [Norwegian] scabies) $(5,8)$. The pruritic response and secondary skin manifestations, which begin three to six weeks after initial infection, are mediated by inflammatory and allergylike reactions to mite products (4). The burrow is a wavy line that is detectable most frequently in the finger webs, on the flexor surfaces of the wrists, on the elbows, in the axillae, on the buttocks and genitalia (5). Papules, nodules and vesicles are also described as secondary lesions that include excoriations, eczematous eruptions, crusting and infections (9).

Although history and examination of the morphology and the distribution of skin lesions can be clues, definitive diagnosis of scabies infection relies on identification of mites, eggs or feces in skin scrapings or biopsies. Diagnosis based on symptoms and an empirical trial of scabies treatment is problematic because it can lead to diagnostic error and frustration, as well as uncertainty when patients do not improve.

Skin scrapings are central to diagnosis and involve the application of one or two drops of mineral oil to a suspected lesion, which is then scraped or shaved with a scalpel or a microscope slide. The specimens are examined directly under a low-power light microscope (8). A small number of mites on an infected individual can often negate or delay a

${ }^{1}$ Division of Infectious Diseases, Department of Medicine, McGill University; ${ }^{2}$ Division of Infectious Diseases, Department of Medicine,

Jewish General Hospital, Montreal, Quebec

Correspondence: Dr Victor Leung, Division of Infectious Diseases, McGill University, 1650 Cedar Avenue, Room A5-156, Montreal,

Quebec H3G 1A4. Telephone 514-934-1934 ext 42811, fax 514-943-8432, e-mail victor.leung@mail.mcgill.ca 


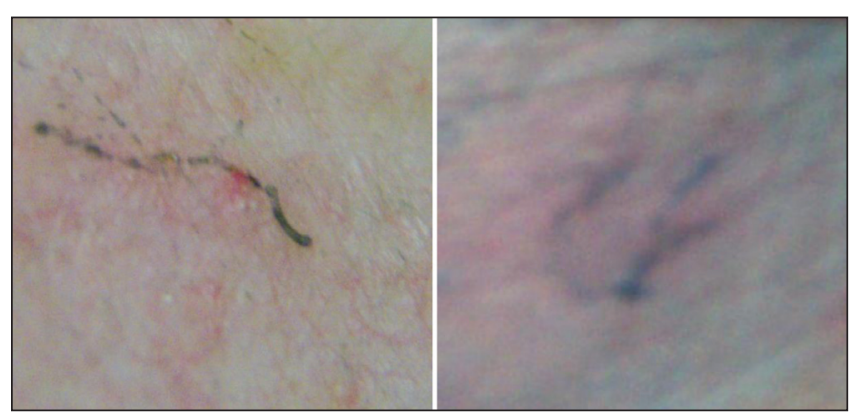

Figure 1) Two examples of the burrow ink test. The underside of a fountain pen is rubbed on the skin and excess ink is wiped off with an alcohol swab. The burrow is visible as a wavy line where the ink has filled the tunnel in the stratum corneum

diagnosis. A simple and often overlooked bedside test is the 'burrow ink test' (BIT), in which fountain pen ink is gently rubbed on a suspicious site. Excess ink is wiped off with an alcohol swab, making the burrow visible as a wavy ink-filled line in the stratum corneum where the mite has tunnelled. We use the BIT in our outpatient infectious diseases clinic to successfully diagnose infections (Figure 1). A published case series (10) reported that the best place to find a lesion was on the medial aspect of the hypothenar area of the hands and wrists.

Recently, in vivo mite identification by 'epiluminescence microscopy', using a dermatoscope, has been studied. This technique relies on identifying a triangular structure, which corresponds to the anterior section of the mite including the mouth part and the two pairs of front legs (11). Indirect diagnostic methods, such as serology have, to date, been unsuccessful in human infections (12). Complementary DNA libraries have been constructed for $S$ scabiei var. hominis, but commercial molecular diagnostic tests have not yet been developed $(13,14)$.

Given its rapid spread in localized epidemics, effective scabies control necessitates rapid diagnosis and treatment. Consequently, we systematically reviewed history, physical examination and diagnostic tests for scabies infection to determine their precision and accuracy. The present study is, to our knowledge, the first systematic review of the diagnosis of scabies infection.

\section{METHODS}

\section{Search strategy}

One of the authors (VL) conducted a Medline search (1965 to 2009) on March 24, 2010, using PubMed. The Embase database was searched using OVID (1941 to 2009) for additional articles. These searches used the medical subject headings (MeSH) "scabies" and "diagnosis", and limited the results to human subjects, and English and French language articles. The reference lists of pertinent articles were reviewed to identify additional studies. A focused search was conducted using the same $\mathrm{MeSH}$ terms combined with other MeSH terms such as "medical history", "physical examination", "sensitivity”, "specificity”, "observer variation”, "mass screening" and/or "self examination", and limited the results to human studies, and English and French language articles. A total of 340 abstracts were screened by one of the authors. The number of abstracts screened was less than the number of citations retrieved because some citations did not have abstracts. In these cases, attempts were made to retrieve the full-text article, but this was not possible in all cases.

\section{Selection criteria}

Abstracts were reviewed to identify those with primary data comparing scabies with a symptom, sign, bedside test or laboratory test. Articles meeting these criteria underwent full-quality assessment using an established methodological filter described in the literature (15). In summary, level 1 studies are independent, blinded comparisons with a reference standard among a large number (sufficient to have narrow confidence limits in the resulting sensitivity, specificity or likelihood ratio [LR]) of consecutive patients suspected of having the target condition. Level 2 studies are independent, blinded comparisons with a reference standard among a small number of consecutive patients suspected of having the target condition. Level 3 studies are independent, blinded comparisons with a criterion standard among nonconsecutive patients suspected of having the target condition. Level 4 studies are nonindependent comparisons with a criterion standard among convenience samples of patients who are considered to have the target condition plus, perhaps, healthy individuals. Level 5 studies are nonindependent comparisons with a criterion standard of uncertain validity among convenience samples of patients and, perhaps, healthy patients. Using this classification scheme, only articles that met or exceeded level 4 criteria were analyzed. The accepted criterion standard was microscopic evidence of scabies in skin scrapings or biopsies.

\section{Extraction of data}

One investigator reviewed all studies and extracted the data regarding test characteristics and study quality. If uncertainty arose, the second investigator independently extracted the data. However, this was not necessary for the review.

\section{Statistical methods}

Sensitivities and specificities for the various findings were calculated whenever possible. LRs were calculated when authors reported findings of patients suspected of being infected with scabies, with both positive and negative skin scrapings. 95\% CIs were calculated according to the efficient score method (corrected for continuity) (16).

\section{RESULTS}

Fourteen full-text articles were retrieved (10 were original diagnostic research articles, but only one of these was a controlled trial: one was a review article, two were case series and one was a case report). None of the studies provided sufficient information to estimate inter- and intraobserver variability. Therefore, the results only focused on test accuracy.

Accuracy of the history and physical examination for the diagnosis of scabies infection

None of the studies reviewed evaluated the accuracy of history and physical examination for the diagnosis of scabies. Only one review article stated that a history of diffuse itching and visible lesions associated with at least two typical locations of scabies, or a household member with itching, has 100\% sensitivity and 97\% specificity (5). The primary source for the review lacked an acceptable reference standard, namely an undefined clinical diagnosis by a dermatologist (17). However, it is only fair to point out that the study was designed to improve treatment of a very large number of individuals in West Africa under conditions in which access to a microscope was limited or absent. In the setting of high prevalence, one could argue that a clinical diagnosis by an experienced clinician can be an appropriate reference standard. However, because the study did not meet the a priori inclusion criteria, it was excluded from the present analysis.

\section{Accuracy of specimen collection methods for the microscopic diagnosis of scabies infection}

The current literature supports the use of a blade (or the edge of a microscope slide) to scrape laterally across the skin (8). The specimen is then placed on a glass slide for examination. Two less-invasive techniques have been introduced and both attempt to remove the skin with glue. However, these studies did not meet criteria for inclusion in the present analysis. One technique involved applying cyanoacrylate glue to a glass slide and then pressing the slide onto the skin for $30 \mathrm{~s}$ followed by detachment (18). The other technique used Scotch tape (3M, USA) that is directly applied to a glass slide (19). The accuracy of these methods could not be calculated based on the information provided in the case series and report.

\section{Accuracy of dermatoscopic techniques for the diagnosis of scabies} infection

The studies comparing dermatoscopy with traditional microscopy are summarized in Table 1. Only one study met level 3 criteria (20). 
TABLE 1

Systematic review of diagnostic studies comparing dermatoscopy versus skin scrapings for the diagnosis of scabies

\begin{tabular}{|c|c|c|c|c|c|c|}
\hline $\begin{array}{l}\text { Diagnostic } \\
\text { method } \\
\text { (reference) }\end{array}$ & $\begin{array}{l}\text { Country, } \\
\text { study venue } \\
\text { (n) }\end{array}$ & $\begin{array}{c}\text { Scabies } \\
\text { prevalence, } \\
\%\end{array}$ & $\begin{array}{l}\text { Sensitivity, } \\
\%(95 \% \mathrm{Cl})\end{array}$ & $\begin{array}{l}\text { Specificity, } \\
\%(95 \% \mathrm{Cl})\end{array}$ & LR (range) & Notes (level of evidence)* \\
\hline $\begin{array}{l}\text { Hand-held } \\
\text { dermatoscope } \\
(10 \times \text { magnification }) \\
(20)\end{array}$ & $\begin{array}{l}\text { France, } \\
\text { dermatology } \\
\text { clinic (245) }\end{array}$ & 52 & 91 (84-95) & 85 (78-92) & $\begin{array}{l}+\mathrm{LR}=6.5(4.1-10.3) \\
-\mathrm{LR}=0.1(0.06-0.2)\end{array}$ & $\begin{array}{l}\text { Patients were eligible if they had pruritus lasting more } \\
\text { than } 1 \text { week without an obvious accountable skin } \\
\text { condition, were referred by a physician for possible } \\
\text { scabies or were given a presumptive diagnosis of } \\
\text { scabies by the clinic dermatologist. Patient } \\
\text { demographics are documented (level 3) }\end{array}$ \\
\hline $\begin{array}{l}\text { Incident light } \\
\text { microscopy } \\
\text { (magnification up } \\
\text { to } 200 \times \text { ) (22) }\end{array}$ & $\begin{array}{l}\text { Italy, } \\
\text { dermatology } \\
\text { clinic (37) }\end{array}$ & 100 & $100(88-100)$ & $\mathrm{N} / \mathrm{A}$ & $\mathrm{N} / \mathrm{A}$ & $\begin{array}{l}\text { There was no description of the protocol for patient } \\
\text { enrollment. Patient demographics were not presented. } \\
\text { Evaluators were nonblinded, and the gold standard } \\
\text { was performed in all patients (level 4) }\end{array}$ \\
\hline
\end{tabular}

${ }^{*}$ The level of evidence is based on a filter described in the literature (15). This classification is summarized in the methods section. $+L R$ Positive likelihood ratio; - LR Negative likelihood ratio; N/A Not applicable

Although all level 4 studies applied the reference standard to all individuals, the evaluators were not blinded to the results (21-23). Data provided in these studies did not permit calculation of LRs. Two case reports examined the role of dermatoscopy, but none met the inclusion criteria for the present systematic review $(11,23,24)$. The typical 'jet with condensation trails' pattern has been reported to be $93 \%$ to $100 \%$ sensitive and $100 \%$ specific in an article (11) that referred to studies by Brunetti et al (21) and Argenziano et al (22). However, in both studies, specificity could not be defined because they were nonindependent comparisons, with all patients diagnosed with scabies. Although the prospective, nonrandomized trial using a hand-held dermatoscope showed a sensitivity and specificity of $91 \%$ and $85 \%$, respectively, the specificity dropped to $80 \%$ when performed by inexperienced dermoscopists (20). On a more pragmatic basis, Dupuy et al (20) found that if treatment was based on clinical diagnosis alone, $27 \%$ of their study population would have been left untreated and been potential disseminators, while $38 \%$ of patients would have been unnecessarily treated. This would have decreased to $10 \%$ and $12 \%$, respectively, if treatment decisions were based on dermatoscopy (20). These results only apply to a population in which disease prevalence is $52 \%$. Finally, one study (25) using high magnification (600x) videodermatoscopy boasted rapid and clear identification of mites, burrows and/or eggs in 62 of 100 patients examined. The authors did not perform the reference standard on any of the patients, claiming that it was not necessary because the structure of the mite could be well characterized in vivo. Of the 38 patients with negative findings, none had any clinical features of scabies after two weeks of follow up (25).

Accuracy of BIT for the diagnosis of scabies infection

Only one study has been conducted with the BIT, and this study met level 4 quality of evidence criteria (10). Seventeen patients with highly pruritic lesions and a history of at least one affected close contact with presumed scabies were enrolled in the study conducted at a French dermatology clinic in 1981. The BIT was first performed and evaluated by two dermatologists. There were 25 BIT-positive lesions, which were then subjected to a superficial shave biopsy, confirming the diagnosis in all 25 lesions. More than one lesion was examined in each patient, yielding a total of 55 lesions. However, in 11 of 30 BIT-negative lesions, shave biopsies were diagnostic for scabies infection. The sensitivity and specificity could not be calculated from the data provided in the article because it was not stated whether all patients had BIT-positive lesions.
Accuracy of nucleic acid detection methods for the diagnosis of scabies infection

One study used polymerase chain reaction followed by ELISA to detect S scabiei DNA from one patient (26). The methods used in this study did not meet the authors predefined quality assessment filter and, thus, the accuracy of this technique could not be calculated. Severe technical limitations have impeded the development of molecular studies on S scabiei.

\section{DISCUSSION}

The present review shows that the diagnosis of scabies infection is often imprecise or speculative. First, a high index of suspicion is needed to diagnose scabies infections because of the diversity of symptoms and presentations. Second, even with a high pretest likelihood, microscopic examination of skin scrapings will often fail to provide a definitive diagnosis because of a low number of mites present in classic scabies infection or due to sampling error. Third, presumptive therapy has been used as a diagnostic test, but this strategy is confounded by ineffective treatment due to scabies drug resistance; the need for repeated treatment due to drug resistance, nonadherence or inadequate environmental control; and variable delay until symptoms are resolved. Moreover, treatment cannot distinguish when a positive response is due to an erroneous diagnosis with spontaneous symptom resolution, or when a negative response is due to treatment resistance or improper treatment application.

The literature on the diagnosis of scabies has significant limitations affecting both internal and external validity. None of the reviewed studies met the criteria for high-quality (level 1 or level 2 ) evidence, based on established methodology filters. The best-available study and the only one that met level 3 criteria was based on a selected population with a scabies prevalence of $52 \%$ (20). Lack of independence between the reference standard and the diagnostic test being assessed, leading to verification bias, is a systemic problem in the literature.

Another methodological issue relates to the nature of the reference standard itself. Skin scraping or biopsy was not obtained for all patients suspected of having scabies in the reviewed studies. Furthermore, using the current reference standard (scraping or biopsy), there are problems associated with excluding cases with negative skin scraping results because this technique is far from being 100\% accurate. Dermatoscopy was originally used for the assessment of pigmented skin lesions. Its use for in vivo detection of S scabiei was suggested by Kreusch (27) in 1992. Proponents of dermatoscopy suggest it permits rapid, noninvasive 


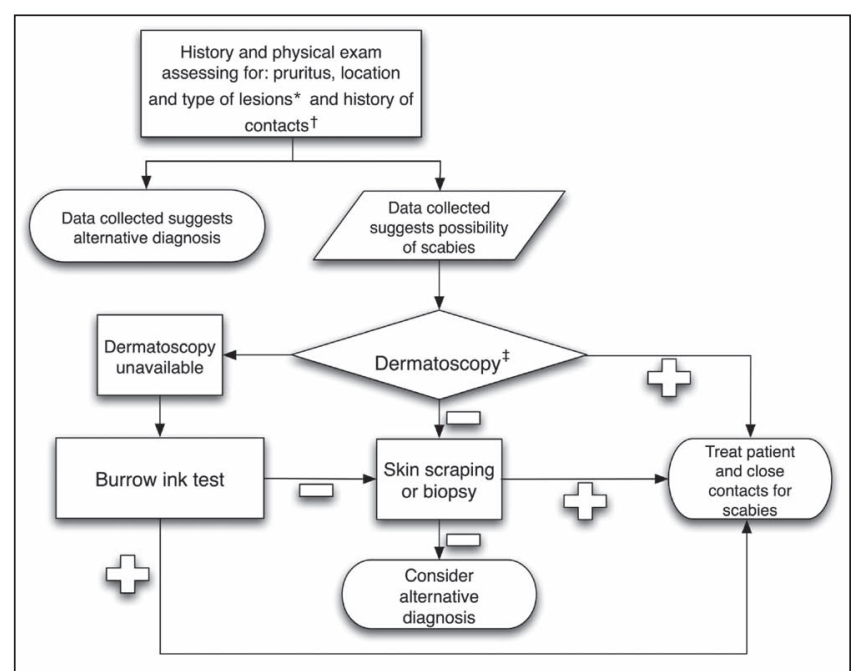

Figure 2) Proposed clinical algorithm for diagnosing scabies. *Primary lesions are typically located in the finger webs, on the flexor surfaces of the wrists, on the elbows, in the axillae, on the buttocks and genitalia, and on the breasts. ${ }^{\dagger}$ Close contact may include family members and sexual partners. Health care workers with a history of caring for patients with scabies should be considered at risk. Use of a hand-held dermatoscope requires training to recognize the typical 'jet with condensation trail' pattern (11)

examination of many suspicious sites without causing pain or discomfort to patients. The practical limitations of dermatoscopy include time and costs. The procedure took from $1 \mathrm{~min}$ to $20 \mathrm{~min}$ in these reviewed studies. Again, the main limitation of dermatoscopy is

\section{REFERENCES}

1. Ramos-e-Silva M. Giovan Cosimo Bonomo (1663-1696): Discoverer of the etiology of scabies. Int J Dermatol 1998;37:625-30.

2. Chosidow O. Scabies and pediculosis. Lancet 2000;355:819-26.

3. Hengge UR, Currie BJ, Jager G, Lupi O, Schwartz RA.

Scabies: A ubiquitous neglected skin disease. Lancet Infect Dis 2006;6:769-79.

4. Heukelbach J, Feldmeier H. Scabies. Lancet 2006;367:1767-74.

5. Chosidow O. Clinical practices. Scabies. N Engl J Med 2006;354:1718-27.

6. de Beer G, Miller MA, Tremblay L, Monette J. An outbreak of scabies in a long-term care facility: The role of misdiagnosis and the costs associated with control. Infect Control Hosp Epidemiol 2006;27:517-8.

7. Brook I. Microbiology of secondary bacterial infection in scabies lesions. J Clin Microbiol 1995;33:2139-40.

8. Walton SF, Currie BJ. Problems in diagnosing scabies, a global disease in human and animal populations. Clin Microbiol Rev 2007;20:268-79.

9. Chouela E, Abeldano A, Pellerano G, Hernandez MI. Diagnosis and treatment of scabies: A practical guide. Am J Clin Dermatol 2002;3:9-18.

10. Woodley D, Saurat JH. The burrow ink test and the scabies mite. J Am Acad Dermatol 1981;4:715-22.

11. Prins C, Stucki L, French L, Saurat JH, Braun RP. Dermoscopy for the in vivo detection of Sarcoptes scabiei. Dermatology 2004;208:241-3.

12. Kuhn C, Lucius R, Matthes HF, Meusel G, Reich B, Kalinna BH. Characterisation of recombinant immunoreactive antigens of the scab mite Sarcoptes scabiei. Vet Parasitol 2008;153:329-37.

13. Casais R, Prieto M, Balseiro A, Solano P, Parra F, Martin Alonso JM. Identification and heterologous expression of a Sarcoptes scabiei cDNA encoding a structural antigen with immunodiagnostic potential. Vet Res 2007;38:435-50.

14. Alasaad S, Rossi L, Soriguer RC, et al. Sarcoptes mite from collection to DNA extraction: The lost realm of the neglected parasite. Parasitol Res 2009;104:723-32. excluding false negatives, because there is no reference standard for ruling out or verifying the absence of scabies infection.

Although the BIT has not been studied extensively, we believe that its minimal cost and adverse events, in addition to its rapid turnaround time, makes it a useful, but unproven diagnostic test. With experience, when the BIT is positive, treatment for scabies can be started without having to perform skin scrapings. For practitioners unfamiliar with the BIT, we recommend follow-up of BIT-positive lesions by skin scrapings or punch biopsies, until the practitioner is sufficiently skilled in recognizing a positive BIT.

The present study confirms the lack of accurate and easily applicable methods for diagnosing scabies or for assessing the efficacy of treatment to eliminate mites. Nonetheless, when faced with uncertainty, one should still attempt to make a diagnosis. Hence, we include a practical algorithm to help diagnose scabies infection (Figure 2). This algorithm includes history, clinical examination and use of skin scrapings, BIT or dermatoscopy. It is important to remember, however, that a negative result from any of these tests does not necessarily exclude a diagnosis of scabies infection. In that situation, clinical experience and judgment come into play and this may even include, in some cases, a treatment trial.

CONFLICTS OF INTEREST: The authors have no conflicts of interest to declare.

AUTHOR CONTRIBUTIONS: Victor Leung and Mark Miller conceived the idea for the study. Victor Leung reviewed all articles and drafted the manuscript. Victor Leung and Mark Miller critically revised the manuscript for important intellectual content, and both authors approved the final manuscript for submission.
15. McGee S, Abernethy WB III, Simel DL. The rational clinical examination. Is this patient hypovolemic? JAMA 1999;281:1022-9.

16. Julious SA. Two-sided confidence intervals for the single proportion: Comparison of seven methods by Robert G Newcombe, Statistics in Medicine 1998;17:857-872. Stat Med 2005;24:3383-4.

17. Mahe A, Faye O, N'Diaye HT, et al. Definition of an algorithm for the management of common skin diseases at primary health care level in sub-Saharan Africa. Trans R Soc Trop Med Hyg 2005;99:39-47.

18. Neynaber S, Muehlstaedt M, Flaig MJ, Herzinger T. Use of superficial cyanoacrylate biopsy (SCAB) as an alternative for mite identification in scabies. Arch Dermatol 2008;144:114-5.

19. Katsumata K. Simple method of detecting Sarcoptes scabiei var hominis mites among bedridden elderly patients suffering from severe scabies infestation using an adhesive-tape. Intern Med 2006;45:857-9.

20. Dupuy A, Dehen L, Bourrat E, et al. Accuracy of standard dermoscopy for diagnosing scabies. J Am Acad Dermatol 2007;56:53-62.

21. Argenziano G, Fabbrocini G, Delfino M. Epiluminescence microscopy. A new approach to in vivo detection of Sarcoptes scabiei. Arch Dermatol 1997;133:751-3.

22. Brunetti B, Vitiello A, Delfino S, Sammarco E. Findings in vivo of Sarcoptes scabiei with incident light microscopy. Eur J Dermatol 1998;8:266-7.

23. Bauer J, Blum A, Sonnichsen K, Metzler G, Rassner G, Garbe C. Nodular scabies detected by computed dermatoscopy. Dermatology 2001;203:190-1.

24. Neynaber S, Wolff H. Diagnosis of scabies with dermoscopy. CMAJ 2008;178:1540-1.

25. Lacarrubba F, Musumeci ML, Caltabiano R, Impallomeni R, West DP, Micali G. High-magnification videodermatoscopy: A new noninvasive diagnostic tool for scabies in children. Pediatr Dermatol 2001;18:439-41.

26. Bezold G, Lange M, Schiener R, et al. Hidden scabies: Diagnosis by polymerase chain reaction. Br J Dermatol 2001;144:614-8.

27. Kreusch J. Incident light microscopy: Reflections on microscopy of the living skin. Int J Dermatol 1992;31:618-20. 


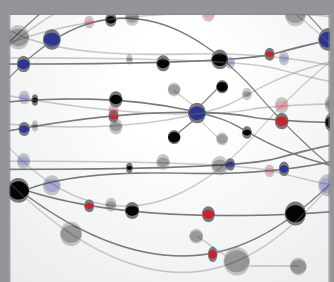

The Scientific World Journal
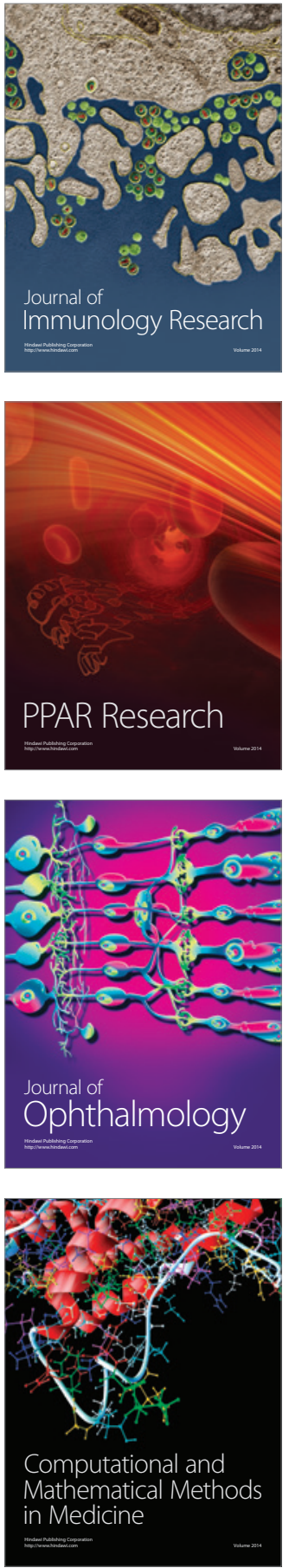

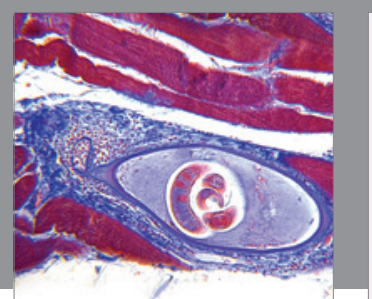

Gastroenterology Research and Practice

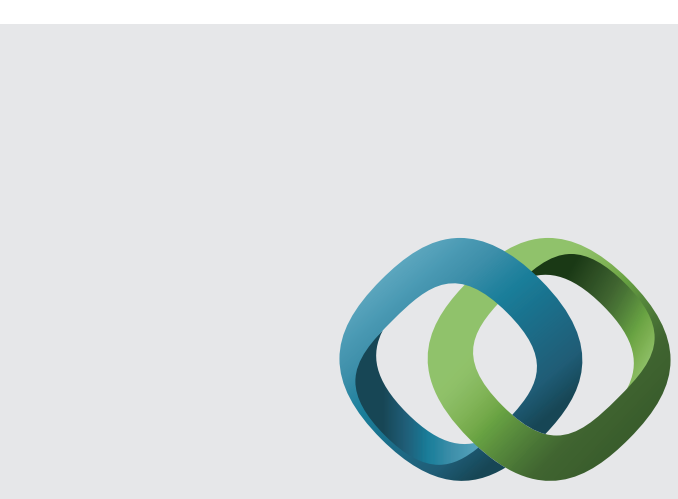

\section{Hindawi}

Submit your manuscripts at

http://www.hindawi.com
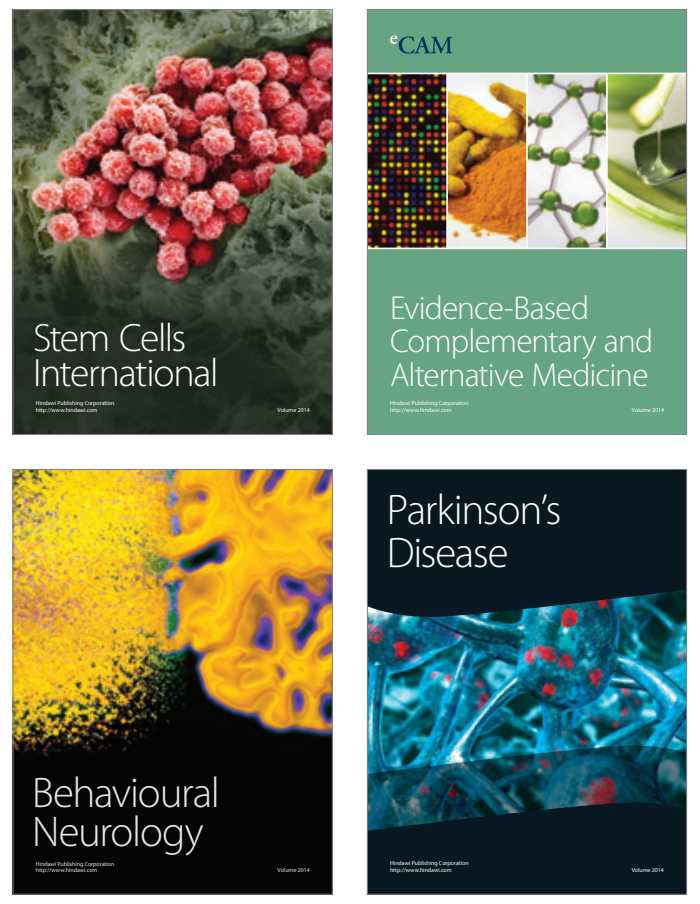
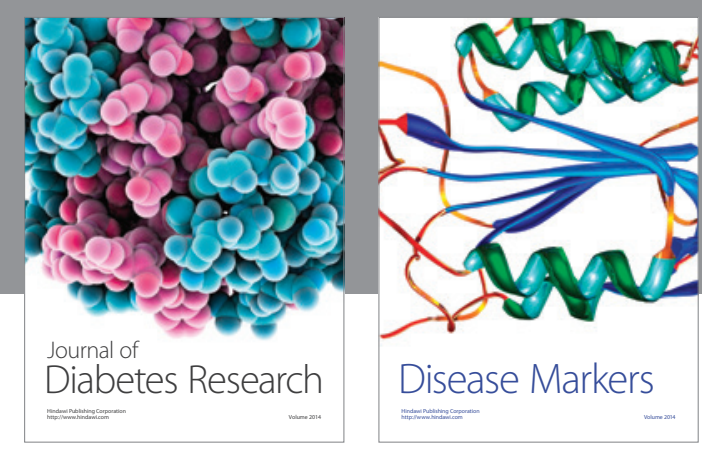

Disease Markers
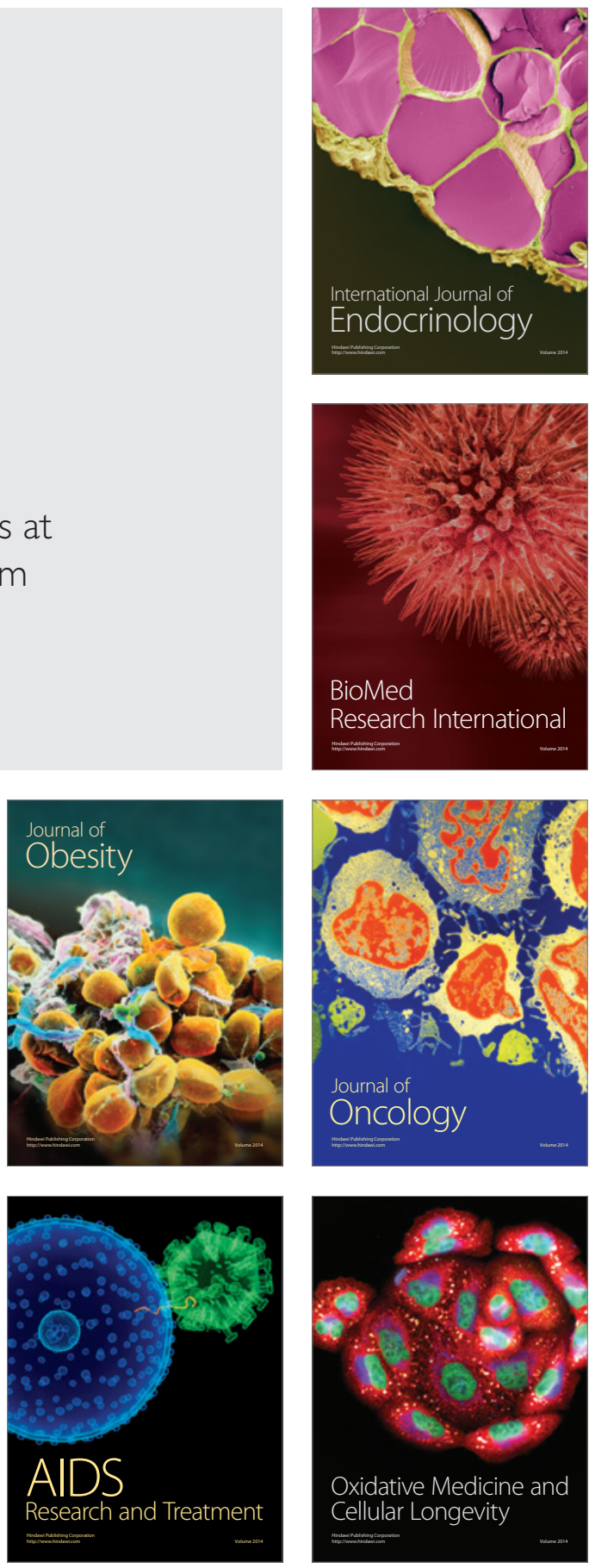